\title{
Gübrelemenin Sakız Fasulyesinin (Cyamopsis tetragonoloba (L.) Taub.) Ot Verimi ve Kalitesine Etkileri
}

\author{
Müge BATIRCA ${ }^{1}$ \\ Ahmet GÖKKUŞ² \\ Firat ALATÜRK ${ }^{2}$ \\ Selçuk BİRER ${ }^{3}$ \\ ${ }^{1}$ Ziraat Yüksek Mühendisi, ÇANAKKALE \\ ${ }^{2}$ ÇOMÜ Ziraat Fakültesi Tarla Bitkileri Bölümü, ÇANAKKALE \\ ${ }^{3}$ ÇOMÜ Bayramiç MYO, ÇANAKKALE \\ $\triangle$ : agokkus@yahoo.com
}

Geliş (Received): 03.11.2017

Kabul (Accepted): 15.12.2017

\begin{abstract}
ÖZET: Ülkemizde yetiştirilen yazlık baklagil yem bitkileri türü oldukça sınırlıdır. Bu bakımdan sakız fasulyesinin önemli bir seçenek olabileceği düşüncesiyle bu araştırma planlanmış ve çalışmada farklı gübre çeşidi ve dozlarının sakız fasulyesinin verim ve kalite özellikleri üzerindeki etkileri araştırılmıştır. Araştırma Çanakkale Onsekiz Mart Üniversitesi Dardanos Yerleşkesi Ziraat Fakültesi uygulama alanında 2015 ve 2016 yılları yaz döneminde yürütülmüsstür. Tesadüf blokları deneme desenine göre 3 tekerrürlü olarak kurulan denemede, 3 azot $(0,3,6$ kg da1) ve 5 fosfor $(0,3,6,9,12 \mathrm{~kg}$ da-1) dozunun kombinasyonlar test edilmiştir. Araştırma sonuçlarına göre, en yüksek yeşil ve kuru ot verimi $3 \mathrm{~kg} / \mathrm{da} \mathrm{N}$ ve $6 \mathrm{~kg} / \mathrm{da} \mathrm{P} 2 \mathrm{O} 5$ uygulamasında elde edilmiştir. Bunun yanında otun en yüksek ham protein ve ham kül oranları ile en düşük NDF ve ADF oranları dekara $6 \mathrm{~kg} \mathrm{~N}$ ve $12 \mathrm{~kg}$ P2O5 uygulanan parsellerde belirlenmiştir. Sonuç olarak, Çanakkale ve benzeri çevrelerde sakız fasulyesi yetiştiriciliğinde yüksek ot üretimi için dekara $3 \mathrm{~kg} \mathrm{~N}$ ve $6 \mathrm{~kg}$ P2O5, besleme değeri yüksek ot üretimi için ise dekara $6 \mathrm{~kg} \mathrm{~N} \mathrm{ve} 12 \mathrm{~kg}$ P2O5 verilmesinin uygun olacağı öngörülmüştür.
\end{abstract}

Anahtar Sözcükler: Sakız fasulyesi, gübre dozu, ham protein, ham kül, ot verimi

\section{Effect of Fertilization on the Yield and Quality of Hay of Cluster Bean (Cyamopsis tetragonoloba (L.) Taub.)}

\begin{abstract}
The growing species of leguminous fodder crops are rather limited in our country. In this regard, this research was planned with the thought that the cluster bean might be an important option, and the effects of different kind and doses of fertilizer on the yield and quality characteristics of cluster bean were investigated in this study. The experiment was conducted in summer season of the years 2015 and 2016 in the Research and Application Area of the Faculty of Agriculture of Çanakkale Onsekiz Mart University situated in Dardanelles Campus. Combinations of three nitrogen $(0,3,6 \mathrm{~kg}$ da- 1$)$ and 5 phosphorus $(0,3,6,9,12 \mathrm{~kg}$ da-1) doses were tested in the experiment designed according to the randomized complete block design with three replications. According to the results, the highest green and dry hay yield were obtained from the treatments of $3 \mathrm{~kg} / \mathrm{da} \mathrm{N}$ and $6 \mathrm{~kg} / \mathrm{da} \mathrm{P} 2 \mathrm{O} 5$. In addition, the highest ratio of crude protein and crude ash, and the lowest NDF and ADF ratios in the hay were determined in plots fertilized with $6 \mathrm{~kg} \mathrm{~N} / \mathrm{da}$ and $12 \mathrm{~kg} \mathrm{P} 2 \mathrm{O} 5 / \mathrm{da}$. From the results of the study, it was concluded that the application of $3 \mathrm{~kg} \mathrm{~N} / \mathrm{da}$ and $6 \mathrm{~kg} \mathrm{P2O5/da} \mathrm{for} \mathrm{obtaining} \mathrm{high} \mathrm{hay} \mathrm{yield} \mathrm{and} 6 \mathrm{~kg} \mathrm{~N} / \mathrm{da}$ and $12 \mathrm{~kg}$ P2O5/da for high hay quality could be recommended for the cultivation of cluster bean in Çanakkale and similar ecological zones.

Keywords: Cluster bean, fertilizer dose, crude protein, crude ash, hay yield
\end{abstract}

\section{GíRiş}

Sakız fasulyesi, kurak ve yarı kurak bölgelerin kumlu topraklarında kurağa dayanıklı, derin köklenen bir y1llık bir baklagildir. Çimlenmesi için en uygun toprak sicaklığ $21-25^{\circ} \mathrm{C}$ civarındadır (Hymowitz ve Matlock, 1963). Anavatanı Hindistan ve Pakistan olan sakız fasulyesi, dünyada kurak ve yarı kurak, tropiksubtropik bölgelerde yetişebilen çalımsı formda bir baklagildir (Dougles, 2005). Derin kök sistemine sahip olmasının yanı sıra terleme oranı düşük olduğundan dolayı kurak bölgelerde rahatlıkla yetişerek hayvanların kaba yem ihtiyacını karşılamada kullanılmaktadır (Paleg ve Aspinal, 1981). Asya'da sebze, yem, yeşil gübre ve toprak koruyucu örtü olarak yetiştirilmektedir (Arora ve Pahuja, 2008; Rao ve Shahid, 2011). Tabandaki boğumlarından çıkan çok sayıda güçlü dallara sahip, 0.5-3.0 m yüksekliğine kadar boylanan, s1k dallı, kendine döllenen bir bitkidir. Tohumları \%27.0-32.2 oranında protein ve $\% 50$ besidokusuna sahip olup, besidokunun \%42'si zamktır (guar zamkı) (Whistler ve Hymowitz, 1979). Sakız fasulyesi esasen zamk ve kıvam artırıcı jel üretimi amacıyla yetiştirilse de, sebze, kaba yem, kesif yem, toprak üstü koruyucu bitki ve tohumluk için de üretilmektedir (Dabas ve ark., 1995). Kâğıt, gıda, madencilik, kozmetik ve ilaç sanayi de kullanım alanları içerisindedir (Pawlik ve Laskowski, 2006; NRAA, 2014). Bitkinin bütün kısımları yararlı olmasının yanında, bağladığı ortalama $3 \mathrm{~kg} \mathrm{da}^{-1} \mathrm{~N}$ ile toprağı da 1slah edebilmektedir.

Ülkemizde yazlık baklagil yem bitkileri türleri sınırlı sayıda olup, üretimleri çok azdır. Bu konuda sakız fasulyesi yazlık baklagil yem bitkisi olabilecek durumdadır. Özellikle sanayi bitkilerinin yoğun yetiştirildiği bölgelerde yem bitkileri ekim alanlarının 
artırılması için, yazlık ana ve ara ürün (2. ürün) olarak baklagil yem bitkilerinin ekim nöbetine dâhil edilmesi bir gerekliliktir. Ülkemizin bilhassa güney ve batı kıyı bölgeleri bunun için oldukça elverișli bir iklime sahiptir (Açıkgöz ve ark., 2004).

$\mathrm{Bu}$ sebeple çalışmada yazlık yem bitkisi türlerine seçenek olabilecek sakız fasulyesinin Çanakkale koşullarında farklı gübre çeşit ve dozlarının ot verimi ve kalitesine etkileri ele alınmıştır.

\section{MATERYAL ve YÖNTEM}

Araştırma Çanakkale Onsekiz Mart Üniversitesi Dardanos Yerleşkesi Ziraat Fakültesi uygulama alanında 2015 ve 2016 yıllarında yürütülmüştür. Denemenin ilk y1lında aylık ortalama sıcaklık $17.8^{\circ} \mathrm{C}$, ikinci yıl ise $16.0^{\circ} \mathrm{C}$ olarak ölçülmüştür. Uzun yıllara ait sicaklık ortalaması ise $15.4^{\circ} \mathrm{C}$ olmuştur. Yıllık toplam yağış miktarları ilk yıl $650.1 \mathrm{~mm}$, ikinci yıl $443.6 \mathrm{~mm}$ ve uzun yillar ortalamasinda $670.2 \mathrm{~mm}$ olarak kaydedilmiştir. Denemenin alanının toprakları kireçli ve killi-tınlı olup hafif alkali özellik göstermekte ( $\mathrm{pH}$ 7.94), tuzluluk tehlikesi görülmemektedir (\%0.04). Bu topraklar organik madde (\%1.77), toplam azot $\mathrm{N}$ (\%0.09), fosfor $\mathrm{P}$ (7.50 ppm) bakımından yetersizdir. Mikro elementler bakımından potasyum, demir, bakır, mangan toprakta yeterli bulunup kalsiyum ve magnezyum fazla miktarda bulunmaktadır. Çinko ise yetersiz görülmüştür (Anonim, 2015). Araştırmada bitki materyali olarak sakı fasulyesinin (Cyamopsis tetragonoloba (L.) Taub.) Hindistan'dan temin edilen Pusa Nevbahar/Sadabahar çeşidi kullanılmıştır. Denemede 3 azot $\left(0,3,6 \mathrm{~kg} \mathrm{da}^{-1}\right)$ ve 5 fosfor $(0,3,6,9$, $\left.12 \mathrm{~kg} \mathrm{da}^{-1}\right)$ dozunun ot verimi ve kalitesi üzerine etkileri incelenmiştir. Tesadüf blokları deneme desenine göre 3 tekerrürlü olarak kurulan denemede, her parsel $5 \mathrm{~m}$ uzunluğunda $30 \mathrm{~cm}$ aralıklı 5 siradan meydana gelmiştir. Deneme süresince bitkiler çıkış yaptıktan sonra elle yabancı ot mücadelesi yapılmıştır. Bitkiler damlama sulama sistemi ile sulanmıştır. Ot hasadı çiçeklenme sonu ile alt baklaların olgunlaşmaya başladığı zaman hasat edilmiştir. Araştırmada yeşil ve kuru ot verimleri ile otun ham protein, ham kül, NDF ve ADF oranları incelenmiştir. Ham kül ve ham protein oranları AOAC (1990)'a göre, NDF ve ADF içerikleri ise Van Soest ve ark. (1991) tarafindan geliştirilen yönteme göre belirlenmiştir. Çalışmadan elde edilen verilerin varyans analizlerinde iki yıllık ortalama değerler kullanılmıştır. Varyans analizi tesadüf blokları deneme desenine uygun olarak SAS istatistik paket programı ile yapılmıştır (SAS, 1999). Ortalamaların karşılaştırılmasında LSD çoklu karşılaştırılma testi kullanılmıştır.

\section{BULGULAR ve TARTISSMA}

Ot verimi: Sak1z fasulyesinde azot ve fosfor uygulamalarının yeşil ot verimine etkileri istatistiki olarak önemli bulunmuştur. En yüksek yeşil ot verimi azotun $6 \mathrm{~kg} \mathrm{da}^{-1}\left(2390.3 \mathrm{~kg} \mathrm{da}^{-1}\right)$ ve fosforun $6 \mathrm{~kg} \mathrm{da}^{-1}$ dozu uygulanan parsellerde $\left(2413.5 \quad \mathrm{~kg} \quad \mathrm{da}^{-1}\right)$ belirlenmiştir (Çizelge 1).

Gübrelemenin sakız fasulyesinin kuru ot verimine etkisi sadece azotlu gübre uygulamasında önemli çıkmıştır. Buna göre en yüksek kuru ot verimi $(623.4 \mathrm{~kg}$ $\mathrm{da}^{-1}$ ) azotun $3 \mathrm{da}^{-1}$ verildiği parsellerde belirlenirken, en az verim $\left(504.6 \mathrm{~kg} \mathrm{da}^{-1}\right)$ azot uygulanmayan parsellerde tespit edilmiştir (Çizelge 1).

Çizelge 1. Azot ve fosfor ile gübrelenen sakız fasulyesinin yeşil ve kuru ot verimleri $(\mathrm{kg} / \mathrm{da})$

\begin{tabular}{|c|c|c|c|c|}
\hline \multirow{2}{*}{ Fosfor dozları } & \multicolumn{3}{|c|}{ Azot dozları } & \multirow{2}{*}{ Ortalama } \\
\hline & $\mathbf{0}$ & $\mathbf{3}$ & 6 & \\
\hline \multicolumn{5}{|c|}{ Yeşil ot verimi } \\
\hline $\mathbf{0}$ & 1806.8 & 2355.1 & 2232.8 & $2131.6 \mathrm{~B}$ \\
\hline 3 & 1765.2 & 2412.3 & 2267.5 & $2148.3 \mathrm{~B}$ \\
\hline 6 & 2121.1 & 2550.4 & 2569.1 & $2413.5 \mathrm{~A}$ \\
\hline 9 & 2026.1 & 2379.4 & 2161.3 & $2188.9 \mathrm{~B}$ \\
\hline 12 & 2388.7 & 2254.2 & 2280.0 & $2307.6 \mathrm{AB}$ \\
\hline Ortalama & $2021.6 \mathrm{~B}$ & $2302.1 \mathrm{~A}$ & $2390.3 \mathrm{~A}$ & \\
\hline \multicolumn{5}{|c|}{$\mathrm{P}_{\mathrm{N}}: 0.0001, \mathrm{P}_{\mathrm{P}}: 0.0636, \mathrm{P}_{\mathrm{N} * \mathrm{P}}: 0.1577$} \\
\hline \multicolumn{5}{|c|}{ Kuru ot verimi } \\
\hline $\mathbf{0}$ & 454.2 & 617.2 & 581.6 & 551.0 \\
\hline 3 & 414.4 & 599.3 & 604.5 & 539.4 \\
\hline 6 & 543.2 & 722.2 & 648.7 & 638.0 \\
\hline 9 & 476.9 & 603.4 & 544.4 & 541.6 \\
\hline 12 & 634.2 & 575.0 & 583.9 & 597.7 \\
\hline Ortalama & $504.6 \mathrm{~B}$ & $623.4 \mathrm{~A}$ & $592.6 \mathrm{~A}$ & \\
\hline Önemlilik & $\mathrm{P}_{\mathrm{N}}: 0.0007, \mathrm{P}_{\mathrm{P}}: 0$ & 2201 & & \\
\hline
\end{tabular}

Gübreleme ile yeşil ve kuru ot veriminde önemli artış olmuştur. Azot ve fosfor bitkilerde en çok bulunan ve bitkilerin en fazla ihtiyaç duydukları elementlerdir. Bitkilerde fotosentez, dolayısıyla kütle artışında önemli görevlere sahiptirler. Örneğin azot aminoasit, protein, nükleik asitler, ATP ve klorofil gibi bitki hücresindeki genetik ve metabolizma olaylarında görev yapan bileşiklerin temelini oluşturmaktadır. Fosfor da benzer şekilde nükleik asitler ve ATP gibi önemli bileşiklerin yapısında bulunmaktadır. Azot bitkilerde özellikle vejetatif dokuların gelişimini teşvik ederken, fosfor baklagillerde aynı etkilere sahiptir. Bitkinin yeteri kadar 
fosfor alması durumunda kök gelişimi, sap uzunluğu, tohum üretimi, tohum kalitesi ve hastalıklara dayanımı artmaktadır (Hussein ve Alva, 2014). Bu yüzden yapılan pek çok gübreleme araştırmasında (Barros ve ark., 2007; Alatürk, 2012) olduğu gibi bu çalışmada da gübrelemenin verim üzerinde olumlu etkileri ortaya çıkmıştır.

Ham protein (HP) orant: Sakız fasulyesinin HP içeriğine azot ve fosforun etkisi istatistiki olarak önemli olurken, bunların etkileşimi önemsiz olmuştur. En yüksek HP oranı (\%15.95) $6 \mathrm{~kg} / \mathrm{da} \mathrm{N}$ dozunda, en az (\%13.12) ise $\mathrm{N}$ verilmeyen parsellerde tespit edilmiştir. Bunun yanı sıra fosfor uygulamasında ise en yüksek HP içeriği (\%15.85) $12 \mathrm{~kg} /$ da $\mathrm{P}_{2} \mathrm{O}_{5}$ uygulanan, en düşük HP (\%13.27) ise fosfor uygulanmayan parsellerde tespit edilmiştir (Çizelge 2).
Azot ve fosforla gübreleme sakız fasulyesinin otunun HP oranını artırmıştır. Protein azotlu organik bileşik olduğundan, topraktaki azot miktarı arttığında, bitkiler bu azotu alarak proteinlere çevirirler. Böylelikle bitkinin $\mathrm{HP}$ oranı yükselir. $\mathrm{Bu}$ yüzden yapılan gübre çalışmalarında azotun ham protein oranına etkileri olumlu ve önemli bulunmaktadır. Örneğin Erzurum ovasındaki çayırlarda yapılan bir çalışmada, azot dozunun artışına bağlı olarak otun HP oranının arttığ1 (Gökkuş, 1990); taban merada da azotlu gübrelemenin kuru ot verimi ile HP oranını yükselttiği belirlenmiştir (Özaslan, 1996). Benzer sonuçlara Van'da melez misır ile yapılan araştırmada ulaşılmıştır (Çelebi ve ark., 2010). Ayrıca sakız fasulyesi ile ilgili yapılan diğer gübreleme çalışmalarında da azot uygulaması ile otun HP oranında artışlar olduğu kaydedilmiştir (Ayub ve ark., 2011).

Çizelge 2. Azot ve fosfor ile gübrelenen sakız fasulyesinde sapta ham protein, ham kül, NDF ve ADF oranları (\%)

\begin{tabular}{|c|c|c|c|c|}
\hline \multirow{2}{*}{ Fosfor dozları } & \multicolumn{3}{|c|}{ Azot dozları } & \multirow{2}{*}{ Ortalama } \\
\hline & $\mathbf{0}$ & 3 & 6 & \\
\hline \multicolumn{5}{|c|}{ Ham protein oranı } \\
\hline $\mathbf{0}$ & 11.35 & 13.74 & 14.71 & $13.27 \mathrm{D}$ \\
\hline 3 & 12.02 & 14.84 & 15.98 & $14.28 \mathrm{C}$ \\
\hline 6 & 13.23 & 14.99 & 15.88 & $14.70 \mathrm{BC}$ \\
\hline 9 & 14.30 & 15.23 & 15.87 & $15.14 \mathrm{~B}$ \\
\hline 12 & 14.71 & 15.54 & 17.31 & $15.85 \mathrm{~A}$ \\
\hline Ortalama & $13.12 \mathrm{C}$ & $14.87 \mathrm{~B}$ & $15.95 \mathrm{~A}$ & \\
\hline Önemlilik & \multicolumn{4}{|c|}{$\mathrm{P}_{\mathrm{N}}: 0.0001, \mathrm{P}_{\mathrm{P}}: 0.0001, \mathrm{P}_{\mathrm{N} * \mathrm{P}}: 0.0915$} \\
\hline \multicolumn{5}{|c|}{ Ham kül oranı } \\
\hline $\mathbf{0}$ & 8.47 & 7.71 & 7.97 & $8.05 \mathrm{E}$ \\
\hline 3 & 9.49 & 8.65 & 9.04 & $9.06 \mathrm{D}$ \\
\hline 6 & 10.25 & 9.55 & 10.09 & $9.96 \mathrm{C}$ \\
\hline 9 & 11.11 & 10.21 & 11.40 & $10.91 \mathrm{~B}$ \\
\hline 12 & 11.86 & 11.33 & 12.82 & $12.00 \mathrm{~A}$ \\
\hline Ortalama & $10.24 \mathrm{~A}$ & $9.49 \mathrm{~B}$ & $10.27 \mathrm{~A}$ & \\
\hline Önemlilik & $\mathrm{P}_{\mathrm{N}}: 0.0017, \mathrm{P}_{\mathrm{P}}:$ & & & \\
\hline \multicolumn{5}{|c|}{$\frac{\mathrm{P}_{\mathrm{N}}: 0.0017, \mathrm{P}_{\mathrm{P}}: 0.0001, \mathrm{P}_{\mathrm{N} * \mathrm{P}}: 0.5942}{\text { NDF oranı }}$} \\
\hline $\mathbf{0}$ & $37.72 \mathrm{a}$ & $37.76 \mathrm{a}$ & $34.59 \mathrm{def}$ & $36.69 \mathrm{~A}$ \\
\hline 3 & $36.01 \mathrm{~b}$ & $35.60 \mathrm{bc}$ & 34.10 ef & $35.23 \mathrm{~B}$ \\
\hline 6 & 34.84 cde & $35.00 \mathrm{~cd}$ & $33.82 \mathrm{f}$ & $34.55 \mathrm{C}$ \\
\hline 9 & 34.89 cde & $34.69 \mathrm{def}$ & $32.51 \mathrm{~g}$ & $34.03 \mathrm{D}$ \\
\hline 12 & 34.87 cde & $34.18 \mathrm{def}$ & $30.74 \mathrm{~h}$ & $33.26 \mathrm{E}$ \\
\hline Ortalama & $35.66 \mathrm{~A}$ & $35.45 \mathrm{~B}$ & $33.15 \mathrm{~B}$ & \\
\hline \multirow{2}{*}{\multicolumn{5}{|c|}{$\begin{array}{r}\mathrm{P}_{\mathrm{N}}: 0.0001, \mathrm{P}_{\mathrm{P}}: 0.0001, \mathrm{P}_{\mathrm{N} * \mathrm{P}}: 0.0004 \\
\text { ADF oranı }\end{array}$}} \\
\hline & & & & \\
\hline $\mathbf{0}$ & $26.82 \mathrm{a}$ & $25.09 \mathrm{bcd}$ & $23.37 \mathrm{e}$ & $25.09 \mathrm{~A}$ \\
\hline 3 & $26.01 \mathrm{ab}$ & 24.27 cde & $20.84 \mathrm{f}$ & $23.70 \mathrm{~B}$ \\
\hline 6 & $25.36 \mathrm{bc}$ & 24.04 cde & $20.05 \mathrm{fg}$ & $23.15 \mathrm{BC}$ \\
\hline 9 & $24.59 \mathrm{cde}$ & $23.75 \mathrm{de}$ & $19.02 \mathrm{~g}$ & $22.45 \mathrm{CD}$ \\
\hline 12 & 24.37 cde & 24.30 cde & $17.51 \mathrm{~h}$ & $22.06 \mathrm{D}$ \\
\hline Ortalama & $25.43 \mathrm{~A}$ & $24.29 \mathrm{~B}$ & $20.16 \mathrm{C}$ & \\
\hline Önemlilik & \multicolumn{4}{|c|}{$\mathrm{P}_{\mathrm{N}}: 0.0001, \mathrm{P}_{\mathrm{P}}: 0.0001, \mathrm{P}_{\mathrm{N} * \mathrm{P}}: 0.0009$} \\
\hline
\end{tabular}

Ham kül (HK) orant: Sakız fasulyesi otunun HK içeriği üzerine azot ve fosforun etkisi önemli olmuştur. Buna göre en yüksek HK oranı azotun $6 \mathrm{~kg} / \mathrm{da} 10.27$ ), fosforun $12 \mathrm{~kg} / \mathrm{da}$ uygulanan parsellerinde (\%12.00) belirlenmiştir. En az HK ise dekara $3 \mathrm{~kg} \mathrm{~N}$ verilen parseller (\%9.49) ile fosfor verilmeyen parsellerde (\%8.05) belirlenmiştir (Çizelge 2).

Sakız fasulyesinin mineral element içeriği gübrelemeye bağlı olarak artış göstermiştir. Toprakta alınabilir element miktarının artması halinde, bu elementler bitkiler tarafindan daha çok alınarak mineral 
kapsamlarını artırırlar (Brotherson ve Osayande, 1980; Alatürk, 2012). Bunun yanında gübrelemeye bağlı olarak bitkideki ham kül içeriğinin artması, gübrelerin bitkinin besin elementi alımında düzenleyici olarak görev almasından da kaynaklanmaktadır (Ayub ve ark., 2012).

NDF ve ADF oranı: Otun NDF ve ADF içeriklerine azotlu ve fosforlu gübrelerin hem yalın etkileri hem de etkileşimleri istatistiki olarak önemli bulunmuştur. Buna göre en yüksek NDF ve ADF oranları azot ve fosfor verilmeyen parsellerde (NDF \%35.66 ve 36.69, ADF $\% 25.43$ ve 25.09), en düşük NDF ve ADF oranları ise en yüksek gübre uygulanan parsellerde (NDF \%33.15 ve 32,26, ADF \%20.16 ve 22.06) tespit edilmiştir. İki gübrenin birlikte etkisinde de otun en yüksek NDF (\%37.72) ve ADF oranları (\%26.82) kontrol parsellerinde, en düşük oranlar (NDF için \%30.74, ADF için \%17.51) da en yüksek gübre dozlarında belirlenmiştir (Çizelge 2).

Gübreleme ile bitki hücrelerinde hacimsel olarak büyüme meydana gelmektedir. Bu büyümeyle birlikte protoplazma/çeper oranı artmaktadır. Protoplazma oranının artışı çeper bileşenleri olan NDF ve ADF oranlarının azalmasına yol açmaktadır (Alatürk, 2012). Bundan dolayı yapılan çalışmaların çoğunda gübrelemeyle hücre çeperi maddelerinde (NDF, ADF ve ADL) azalmalar kaydedilmiştir (Ball ve ark., 2001; Galdamez-Cabrera ve ark., 2003; Harmoney ve Thompson, 2005).

\section{SONUÇ}

Ülkemizde çiftlik hayvanlarının nitelikli kaba yem ihtiyacının yeterince karşılanamaması önemli bir sorundur. Bu sorunun çözümü için yem bitkileri yetiştiriciliğinin ekim nöbeti sistemleri içine daha çok girmesi ve bu kapsamda desteklenmesi gerekmektedir. $\mathrm{Bu}$ sisteme dahil edilebilecek yazlık baklagil yem bitkileri bakımından ülkemiz yetersiz olmasından dolayı sakız fasulyesi iyi bir seçenek olabilecek durumdadır. Yapılan çalışmada Türkiye'de ilk kez sakız fasulyesi yetiştiriciliğinde gübre çeşit ve dozları denenmiştir. Araştırmada, sakız fasulyesinin yazlık baklagil yem bitkisi olarak yetiştirilebileceği ve bu yetiştiricilikte otun verim ve kalitesini olumlu yönde etkileyen en uygun gübre dozunun ise $3 \mathrm{~kg} / \mathrm{da}$ azot ve $6 \mathrm{~kg} / \mathrm{da}$ fosfor olduğu sonucuna ulaşılmıştır.

\section{KAYNAKLAR}

Açıkgöz E, Uzun A, Bilgili U, Sıncık M 2004. Yield and quality performances of forage type pea strains contrasting leaf types. European J. Agronomy, 22: 85-94.

Alatürk F 2012. Gübrelemenin Çanakkale İli Meralarında Verim ve Otun Kimyasal Bileşimine Etkileri. Yüksek Lisans Tezi. ÇOMÜ Fen Bilimleri Enstitüsü Tarla Bitkileri Anabilim Dalı sayfa 133.

Anonim 2015. Tekirdağ Ticaret Borsası Tarımsal Amaçlı Analiz Laboratuvarı Toprak Analiz Raporu.
AOAC 1990. Official Method of Analysis. Association of Official Analytical 12 Chemists. 15th. Edition. Washington DC., USA. 66-88.

Arora RN, Pahuja SK 2008. Mutagenesis in guar (Cyamopsis tetragonoloba (L.) Taub.). Plant Mutation Reports, 2(1): 7-9.

Ayub M, Khalid M, Tarig M, Nadeem MA, Naeem M 2011. Effect of different seeding densities and nitrogen levels on growth, forage yield and quality attributes of cluster bean (Cyamoposis tetragonoloba Tuab.). J. Agric. Tech., 7(5): 1409-1416.

Ayub M, Nadeem MA, Naeem M, Tahir M, Tariq M, Ahmad, W 2012. Effect of different levels of $P$ and $\mathrm{K}$ on growth, forage yield and quality of cluster bean (Cyamopsis tetragonolobus L.). The Journal of Animal and Plant Sci., 22(2): 479-483.

Ball DM, Collins M, Lacefield GD, Martin NP, Mertens DA, Olson KE, Putnam DH, Undersander DJ, Wolf MW 2001. Understanding Forage Quality. American Farm Bureau Federation Publication, 1-01, Park Ridge.

Barros I, Gaiser T, Lange FM, Römheld V 2007. Mineral nutrition and water use patterns of a maize/cowpea intercrop on a highly acidic soil of the tropic semiarid. Field Crops Research, 101: 26-36.

Brotherson JD, Osayande ST 1980. Mineral concentrations in true mountain mahogany and Utah juniper in associated soils. J. Range Manage., 33:182-185.

Çelebi R, Çelen AE, Çelebi Zorer Ş, Şahar AK 2010. Farklı azot ve fosfor dozlarının misırın (Zea mays L.) silaj verimi ve kalitesine etkisi. Selçuk Üni. Selçuk Tarım ve Gıda Bil. Dergisi, 24(4): 16-24.

Dabas BS, Phogat BS, Rana RS 1995. Genetic resources of cluster bean in India. In: Sharma B (Ed) Genetic Research and Education: Current Trends and the Next 50 Years. Indian Society of Genetics and Plant Breeding, New Delhi, pp 63-70.

Dougles CA 2005. Evaluation of Guar Cultivars in Central and Southern Queensland. Rural Industries Research and Development Corporation, 11p.

Galdamez-Cabrera NW, Coffey KP, Coblentz WK, Turner JE, Scarbrough DA, Jhonson ZB, Gunsaulis JL, Daniels MB, Helwig DH 2003. In situ ruminal degradation of dry matter and fiber from Bermuda grass fertilized with different 161 nitrogen rates and harvested on two dates. Animal Feed Science and Technology, 105(1/4): 185-198.

Gökkuş A 1990. Gübreleme sulama ve otlatma uygulamalarının erzurum ovasındaki çayırların kimyasal ve botanik kompozisyonlarına etkileri. Atatürk Üni. Ziraat Fak. Dergisi, 21(2): 7-24.

Harmoney KR, Thompson CA 2005. Fertilizer rate and placement alters triticale forage yield and quality. Forage and Grazinglands, May: 1-9.

Hussein MM, Alva AK 2014. Growth, yield and water use efficiency of forage sorghum as affected by NPK fertilizer and deficit irrigation. American J. Plant Sci., 5: 2134-2140. 
Hymowitz T, Matlock RS 1963. Guar in the United States. Oklahoma Agricultural Experiment Station Technical Bulletin, 611: 1-34.

NRAA 2014. Potential of Rainfed Guar (Cluster beans) Cultivation, Processing and Export in India. Policy paper No. 3 National Rainfed Area Authority, NASC Complex. DPS Marg, New Delhi-110012, India, $109 \mathrm{p}$.

Özaslan A 1996. Erzurum Ekolojik Şartlarında Taban Mera Bitki Örtülerinin Islahı Üzerine Yırtma, Gübreleme ve Herbisit Uygulamalarının Etkileri. Yüksek Lisans Tezi. Atatürk Üni. Fen Bilimleri Enst. Tarla Bitkileri Anabilim Dalı, Erzurum.

Paleg LG, Aspinal D 1981. The Physiology and Biochemistry of Drought Resistance in Plants. Academic Press, Sydney, Australia. Pp. 251-252.
Pawlik M, Laskowski JS 2006. Stabilization of mineral suspensions by guar gum in potash ore flotation systems. Can. J. Chem. Eng., 84: 532-538.

Rao NK, Shahid M 2011. Potential of cowpea (Vigna unguiculata (L.) Walp.) and guar (Cyamopsis tetragonoloba (L.) Taub.) as alternative forage legumes for the United Arab Emirates. Emir. J. Food Agric., 23(2): 147-156.

SAS 1999. Institute Inc., SAS OnlineDoc $\AA$, Version 9.0, Cary, NC: SAS Institute Inc.

Van Soest PJ, Robertson JD, Lewis BA 1991. Methods 1 for dietary fiber, neutral detergent fiber and nonstarch polysaccharides in relation to animal nutrition. J. Dairy Science, 74: 3583-3597.

Whistler RL, Hymowitz T 1979. Guar Agronomy, Production, Industrial Use and Nutrition. Purdue University Press, West Lafayette, IN, 1-118. 